\title{
Analysis of Slot Leakage Reactance of Submersible Motor with Closed Slots during Starting Transient Operation
}

\begin{abstract}
Xiaohua Bao ${ }^{\dagger}$, Chong Di* and Yong Fang*
Abstract - Generally, closed slots are adopted to reduce the water friction loss in both the stator and the rotor of water filling submersible motor due to the special environment of operation. One of the obvious differences between the traditional induction motors and water filling submersible motors is that the submersible motors only need relatively smaller starting torque. This paper aims to analyze the slot leakage reactance of water filling submersible motor during starting transient operation. An improved analytical method which considered the magnetic saturation of the slot bridge and the skin effect of rotor bars is proposed. The slot permeance factor which has a direct impact on the slot leakage reactance is calculated. Then finite element models with different stator slot types are constructed and search coils are introduced to measure the slot flux linkage. Moreover, the starting performances of the models with two typical stator slots are compared and the flux leakage characteristics are obtained. Finally, the results obtained by finite element method are very close to the results obtained by analytical method.
\end{abstract}

Keywords: Water filling submersible motor, Slot leakage inductance, Starting transient operation, Finite element method

\section{Introduction}

Recently, the application of electrical submersible motor located in subsea well is becoming increasingly common. Closed stator slots and closed rotor slots often appear in water filling submersible motor because of the special operation environment. Slot leakage reactance is a very important electromagnetic parameter of the electrical machine during the electromagnetism design. It is one component of the leakage reactance of the machine. Thus, it has great influence on the performance of the machine especially the starting performance including the starting torque and the staring current. Hence, the calculation of the slot leakage reactance is very important especially in closed slots machines.

Many papers investigated the rotor slot reactance of cage rotors with closed slots. P.D. Agarwal calculated the leakage reactance of induction motors by equivalent circuit, and saturation factors were considered with respect to different angles between the air-gap surface and the slope of the tooth overhang [1]. S.A. Swann analyzed the current distribution over the cross section of a solid cylindrical conductor in a slot with a narrow opening, and determined the complex impedance of the conductor [2]. T.S. Birch described a procedure for the calculation of the specific permeance of the bridge of a closed slot as a function of

$\dagger \quad$ Corresponding Author: School of Electrical Engineering and Automation, Hefei University of Technology, P.R. China. (sukz@ustc.edu)

* School of Electrical Engineering and Automation, Hefei University of Technology, P.R. China. (acdichong@live.com,

rtrmoonsky@163.com)

Received: September 19,2014; Accepted: September 3, 2015 the slot magnetic motive force, and then analyzed the influence of the permeance of closed-slot bridges on the induction-motor-current computation [3]. In fact, the stator leakage reactance of induction motors also attracted many attentions due to the saturation or other factors. There are two theories for calculation of stator leakage reactance, namely, flux method and energy method [4-5]. Pavel Ponomarev calculated the harmonic leakage inductance of permanent-magnet synchronous machines by finite element method and analyzed the effect of slot-and-pole combination on the leakage inductance as well as the performance of tooth coil [6]. S. Salon analyzed the effect of the slot closure and magnetic saturation on induction machine behavior, but gave no reasonable explanation for permeance variations [7]. In addition, an analytic algorithm was presented by Yanping Liang to calculate the strand slot leakage reactance and the discrete integral method was validated by circuit equation method and finite element method [8]. However, few papers studied the slot leakage inductance of motors with both closed-slot-stator and closed-slot-rotor especially during the starting transient operation.

Because of the special operation environment, both the stator and the rotor of water filling submersible motor adopt closed slots to reduce the water friction loss. This type of motor is used to drive centrifugal pumps whose load torque characteristic is the function of pump speed, and the pump needs small break-off torque. In this paper, we improved the analytical methods for calculation of slot permeance factors. The magnetic saturation of stator slot bridges and rotor slot bridges are taken into account. Two 
typical stator slot types were introduced to analyze the stator slot permeance factor which has a decisive impact on the slot leakage reactance. Then rotor slot permeance factor was calculated in consideration of the skin effect of rotor bars during starting transient operation. Finally, the finite element method was introduced to calculate the slot leakage reactance during starting transient operation.

\section{Analytical Analysis of Slot Leakage Reactance During Starting Transient Operation}

\subsection{Analysis of stator slot leakage reactance}

Closed slots often appear in cage motors with ratings from the very lowest powers up to several tens of kilowatts. Due to the special operation environment, both the stator and the rotor of water filling submersible motor adopt closed slots to reduce the water friction loss. In this paper, an improved analytical model is proposed, as shown in Fig. 1.

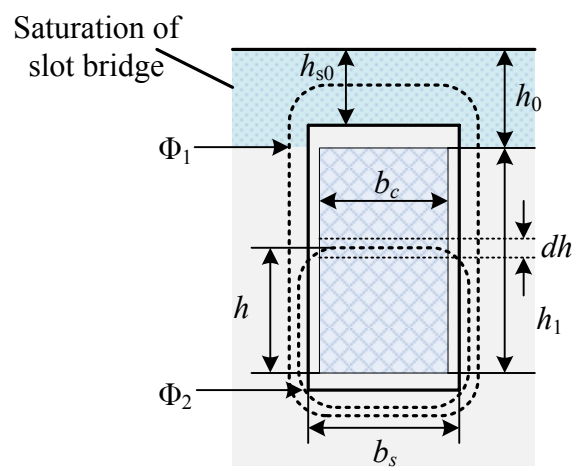

Fig. 1. Leakage flux of a current-carry slot

The accurate calculation of slot leakage reactance is difficult on account of the complex slot structure and the nonlinear material. It should be pointed out that the slot bridge is highly saturated during starting transient operation. Hence, the leakage reactance of the slot bridge cannot be neglected due to the high magnetic reluctivity.

The flux linkage which passes through the slot bridge can be calculated by

$$
\psi_{1}=N_{s}^{2} i \frac{\mu_{1} h_{s 0} l_{e f}}{b_{s}}
$$

where $N_{s}$ is the number of conductors per slot, $i$ is the current in the conductor, $h_{\mathrm{s} 0}$ is the height of the slot bridge, $l_{e f}$ is the effective length of the stator core, $b_{s}$ is the width of the stator slot, and $\mu_{1}$ is the permeability of the highly saturated core.

Similarly, the flux linkage which passes through the slot can be written as

$$
\psi_{2}=N_{s}^{2} i \frac{\mu_{0}\left(h_{0}-h_{s 0}\right) l_{e f}}{b_{s}}+\frac{1}{3} N_{s}^{2} i \frac{\mu_{0} h_{1} l_{e f}}{b_{s}}
$$

where $h_{0}$ is the height between the inner stator surface and the upper surface of the conductor in the stator slot, $h_{1}$ is the height of the equivalent conductor, and $\mu_{0}$ is the permeability of vacuum.

Hence, the leakage inductance per slot can be determined by

$$
L_{s}=N_{s}^{2} \mu_{0} l_{e f} \lambda_{s}
$$

where $\lambda_{\mathrm{s}}$ is the slot permeance factor which can be written as

$$
\lambda_{s}=\frac{\mu_{1}}{\mu_{0}} \frac{h_{s 0}}{b_{s}}+\frac{h_{0}-h_{s 0}}{b_{s}}+\frac{h_{1}}{3 b_{s}} .
$$

Then the slot leakage reactance can be written as $\omega L_{\mathrm{s}}$, where $\omega$ is angular frequency of the current. The permeability of the slot bridge can be obtained by the magnetization curve of the stator silicon steel, as shown in Fig. 2. In convenience of analyzing the relationship between the slot permeance factor and the magnetic flux density, the cubic polynomial is adopted to fit the permeability curve. The cubic polynomial can be written as

$$
y=0.01541-0.02036 \cdot x+0.00901 \cdot x^{2}-0.00133 \cdot x^{3}
$$

where $y$ denotes the value of slot permeance factor, $x$ denotes the value of the magnetic flux density.

The stator designed has a novel slot structure which contains two kinds of slots, as shown in Fig. 3 (a). For the first type slot, the flat part of the rectangular slot is replaced by two broken lines with the inclination $\alpha$. And for the second type slot, the flat part of the rectangular slot is replaced by a flat part and two $1 / 4$ arcs with the radius $R_{0}$. Hence, the deduced expressions of the slot permeance factors for the two type slots can be written as

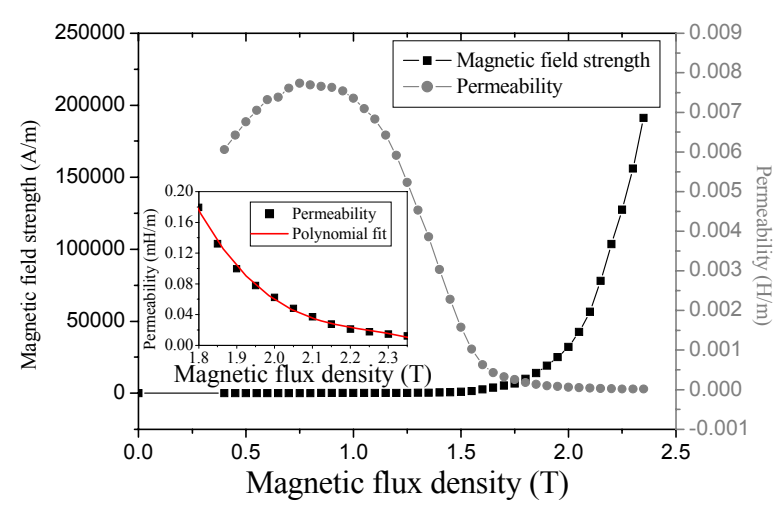

Fig. 2. The magnetization curve of the stator silicon steel 


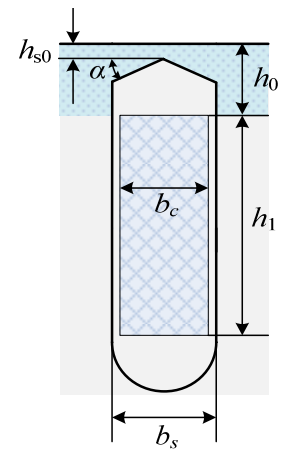

Slot type 1

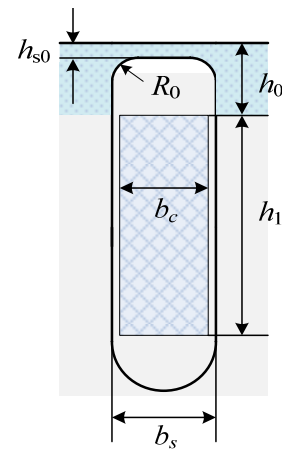

Slot type 2
Stator slot

(a)

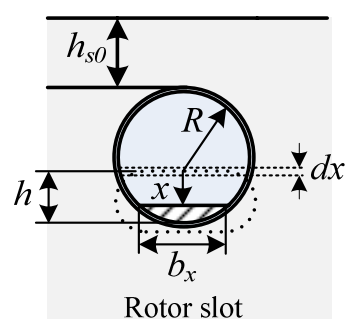

(b)

Fig. 3. (a) Slot structure for Two types of stator slot; (b) Slot structure for rotor slot structure.

$$
\begin{gathered}
\lambda_{s 1}=\frac{\mu_{1}}{\mu_{0}}\left(\frac{h_{s 0}}{b_{s}}+\frac{1}{4} \tan \alpha\right)+\left(\frac{h_{0}-h_{s 0}}{b_{s}}-\frac{1}{4} \tan \alpha\right)+\frac{h_{1}}{3 b_{s}} \\
\lambda_{s 2}=\frac{\mu_{1}}{\mu_{0}}\left(\frac{h_{s 0}}{b_{s}}+1-\frac{\pi}{4}\right)+\left(\frac{\pi}{4}+\frac{h_{0}-h_{s 0}-R_{0}}{b_{s}}\right)+\frac{h_{1}}{3 b_{s}}
\end{gathered}
$$

According to the design experience of submersible motor, the magnetic flux density of the stator slot bridge can be chosen as 2.3T. Then the calculated slot permeance factors are obtained by the expressions, as shown in Fig. 4 (a). It can be seen from Fig.4 (a) that the slot permeance factor of the first type slot varies with the height of the slot bridge as well as the inclination $\alpha$. And the slot permeance factor of the second type slot varies with the height of the slot bridge as well as the radius $R_{0}$, as shown in Fig. 4 (b). The inclination $\alpha$ has a great influence on the slot permeance factor, however, the radius $R_{0}$ has little impact on the slot permeance factor.

\subsection{Analysis of rotor slot leakage reactance}

In this paper, closed slots with round bars are used in the rotor of the water filling submersible motor, as shown in Fig. 3 (b). It should be emphasized that the skin effect as well as saturation effect should be taken into account during the staring transient operation. The inductance of the conductor elements of the upper layer is lower than that

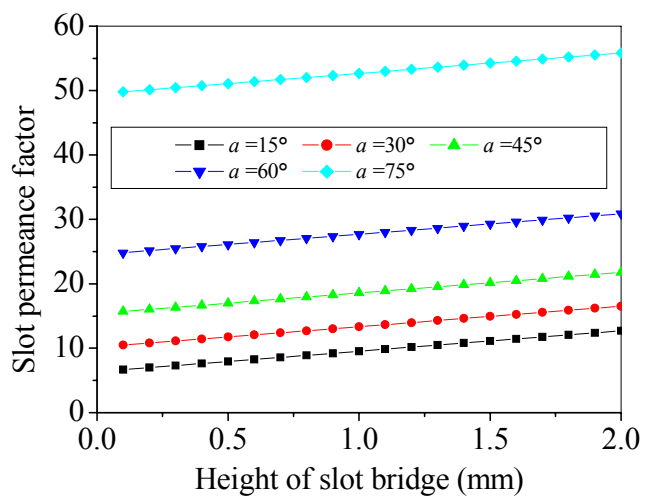

(a)

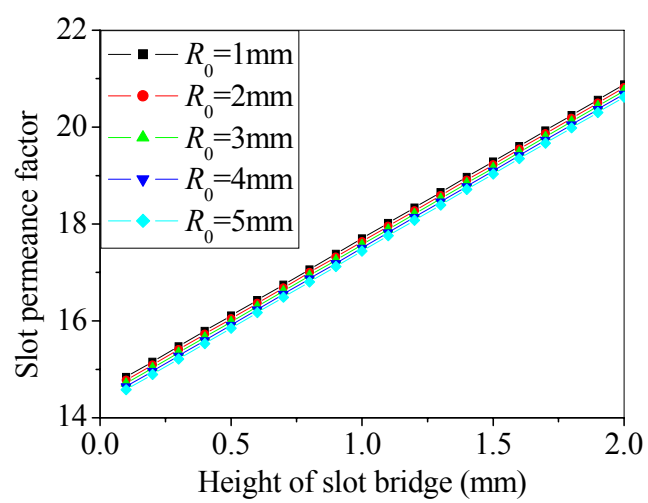

(b)

Fig.4. (a) Calculated stator slot permeance factor for slot type1; (b) Calculated stator slot permeance factor for slot type2.

of the conductor elements at the bottom, and therefore the current density in the upper section of the slot is higher than the current density at the bottom. Since the copper bars are pressed into the rotor slots, the gap between the bars and the slots can be neglected. The total rotor flux linkage can be expressed as

$$
\psi=\psi_{0}+\psi_{1}=i \mu_{0} l_{e f}\left[\frac{\mu_{1}}{\mu_{0}}\left(\frac{h_{s 0}}{2 R}+1-\frac{\pi}{4}\right)+\lambda_{r 1}\right]
$$

where $R$ is the radius of the copper conductor which is approximately equal to the radius of the rotor slot as shown in Fig. 3 (b). And $\lambda_{r 1}$ is the slot permeance factor. In general, the slot permeance factor can be determined as follows

$$
\lambda_{r 1}=\int_{-R}^{R}\left(\frac{S_{x}}{S}\right)^{2} \frac{d x}{b_{x}}
$$

where $S$ is the area of the rotor slot, $S_{x}$ is the area of the copper conductor, the shaded area in Fig.3(b) and $b_{x}$ is the chord length. All the parameters can be expressed as follows 


$$
\left\{\begin{array}{l}
S=\pi R^{2} \\
S_{x}=\frac{1}{2} \pi R^{2}+R^{2} \arcsin \frac{x}{R}+x \sqrt{R^{2}-x^{2}} \\
b_{x}=2 \sqrt{R^{2}-x^{2}}
\end{array}\right.
$$

where $x$ is the distance from the centre of the rotor to the chord, as shown in Fig. 3 (b). Substitute (10) into (9), $\lambda_{r 1}$ is determined to be 0.5597 by the following expression

$$
\begin{gathered}
\lambda_{r 1}=\int_{-R}^{R}\left(R^{2} \arcsin \frac{x}{R}+x \sqrt{R^{2}-x^{2}}+\frac{\pi R^{2}}{2}\right)^{2} \\
\frac{d x}{2 \pi^{2} R^{4} \sqrt{R^{2}-x^{2}}}
\end{gathered}
$$

In consideration of the skin effect, the slot permeance factor of the area with the rotor bar is rewritten as the follow form [4]

$$
\lambda_{r 1, e c}=k_{s e} \lambda_{r 1}
$$

where $k_{s e}$ is the skin effect factor for the permeance. And it can be expressed as [9]

$$
k_{s e}=\frac{3}{2 \xi} \cdot\left(\frac{\sinh 2 \xi-\sin 2 \xi}{\cosh 2 \xi-\cos 2 \xi}\right)
$$

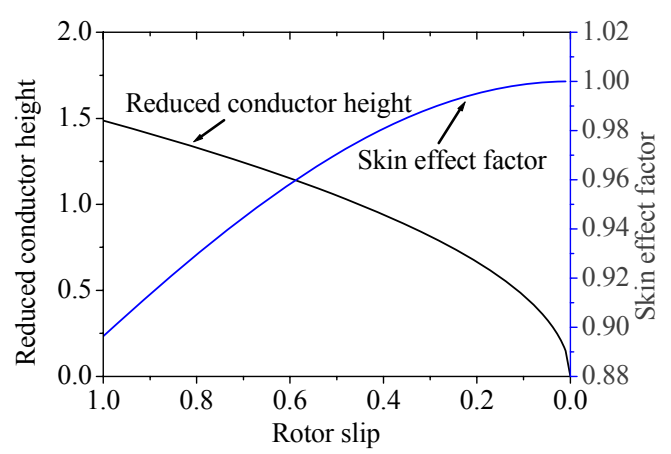

(a)

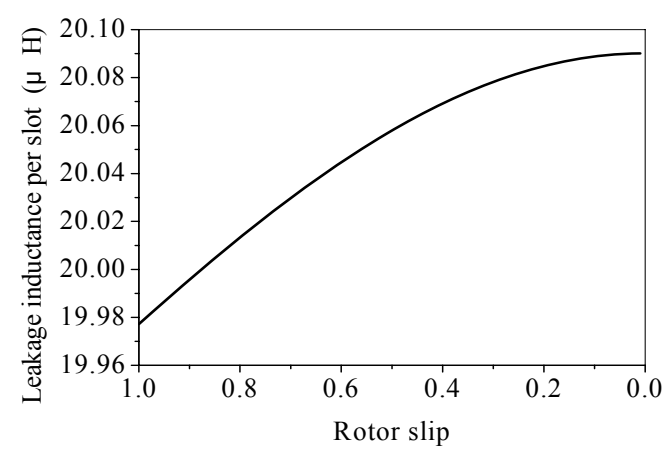

(b)

Fig. 5. (a) Reduced conductor height and skin effect factor; (b) The leakage inductance per slot.
The reduced conductor height $\xi$ can be determined by $\xi=R\left(s \pi f_{1} \mu_{0} \sigma\right)^{1 / 2}$ where $s$ is rotor slip, $f_{1}$ is the frequency of the stator current, and $\sigma$ is the conductivity of the copper conductor.

Hence, the total slot permeance factor for the closed rotor slot is

$$
\lambda_{r}=\frac{\mu_{1}}{\mu_{0}}\left(\frac{h_{s 0}}{2 R}+1-\frac{\pi}{4}\right)+k_{s e} \lambda_{r 1} .
$$

Since the permeability of the rotor slot bridge is much larger than the space permeability, the flux linkages which pass through the rotor slot bridge are the primary components. The reduced conductor height as well as the skin effect factor varies with the rotor slip, as shown in Fig. 5. When the rotor slip changes from 1 to 0 , the skin effect factor ranges from 0.9 to 1 . This value is much smaller than that of the long and narrow slot. In addition, the largest reduced conductor height is about 1.5 when the motor starts. Furthermore, the reduced conductor height decreases with the declining rotor slip.

\section{Finite Element Analysis of Slot Leakage Reactance During Starting Transient}

\subsection{Starting transient operation}

In this paper, a $10-\mathrm{kV} 2800-\mathrm{kW}$ water filling submersible motor was introduced to analyze the slot leakage reactance. Two finite element models were constructed for analyzing the slot leakage reactance of submersible motor during starting transient operation. The height of the slot bridge is set as $1.5 \mathrm{~mm}$ in consideration of the material characteristics. For the first type slot, the inclination $\alpha$ is adopted $45^{\circ}$. And For the second type slot, the radius $R_{0}$ is adopted $3 \mathrm{~mm}$. Four pairs of search coils were placed in the model, three of which were stator search coils. The two sides of the stator search coils are placed in the inner surface of the stator and the bottom of the slot respectively. Similarly, the two sides of the rotor search coils are placed

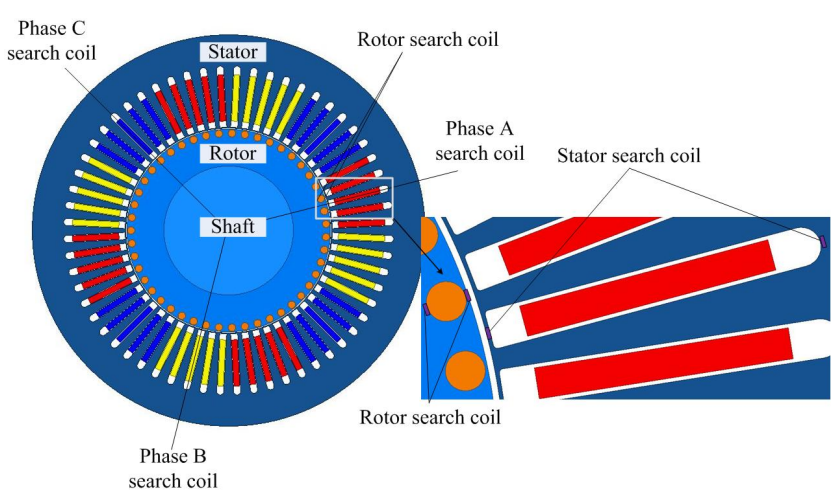

Fig. 6. Finite element model of a $10-\mathrm{kV} 2800-\mathrm{kW}$ water filling submersible motor 
on the outer surface of the rotor and the bottom surface of the copper bar, as shown in Fig. 6 (The figure shows the model of motor with the second type slots).

The transient magnetic field analysis was performed to analyze the staring process. Proper meshes were generated by setting the approximate parameters. In order to take the saturation effect into account, the meshes of the stator slot bridge and the rotor slot bridge are generated with small surface deviations. Moreover, for convenience of considering the skin effect, the skin depth of the rotor bar was calculated by the time-varying parameters.

\subsection{Results and analysis}

The simulation results of the torque, the speed and the current of phase A during starting transient operation are shown in Fig. 7. The water pump load is applied to the motor and the effective value of starting current can be evaluated by the starting current curve.

It can be seen from Fig. 7 that the starting process ends at about $0.9 \mathrm{~s}$. The detailed effective values during the starting transient operation and the stable process can be calculated by root-mean-square values during the processes. The results, as shown in Table 1 , indicate that the torque and the currents of the slot type 2 are smaller than those of the slot type 1 . This can be explained by the different slot leakage reactance of the two type slots. However, both two type slots have a close speed during the stable process.

Table 1. Effective values during starting operation and stable process

\begin{tabular}{c|c|c|c|c}
\hline \multirow{2}{*}{ Item } & \multicolumn{2}{|c|}{ Slot type 1 } & \multicolumn{2}{c}{ Slot type 2 } \\
\cline { 2 - 5 } & $\begin{array}{c}\text { Starting } \\
\text { process }\end{array}$ & $\begin{array}{c}\text { Stable } \\
\text { process }\end{array}$ & $\begin{array}{c}\text { Starting } \\
\text { process }\end{array}$ & $\begin{array}{c}\text { Stable } \\
\text { process }\end{array}$ \\
\hline Torque $(\mathrm{kN} \cdot \mathrm{m})$ & 34.0 & 0.29 & 33.8 & 0.28 \\
\hline Current(A) & 1422.1 & 74.3 & 1414.7 & 69.4 \\
\hline Speed $(\mathrm{rpm})$ & - & 1499.8 & - & 1499.8 \\
\hline
\end{tabular}
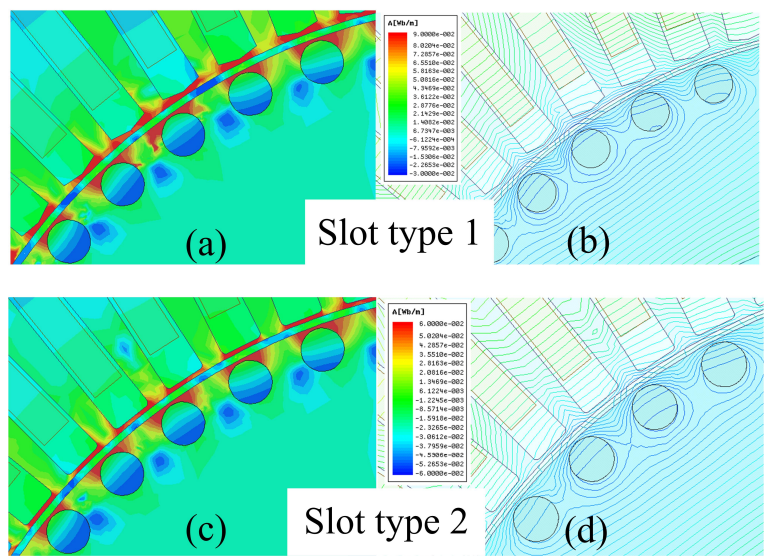

Fig. 8. (a) Magnetic field distribution of slot type1 model; (b) Magnetic line of force of slot type1 model; (c) Magnetic field distribution of slot type2 model; (d) Magnetic line of force of slot type 2 model.
The magnetic field distributions of the model at time $\mathrm{t}=0.1 \mathrm{~s}$ are shown in Fig. 8 . It can be seen from Fig. 8 that the high flux density is generated at some teeth. Since the stator slot is narrow and long, the leakage flux which passes through the stator slot is larger than the leakage flux which passes through the stator slot bridge. Moreover, the flux lines which pass through the slots are almost circumferential.

Take the model with slot type 2 for example, the circumferential distributions of the flux lines are shown in Fig. 9.

In Fig. 9 (a), it is clear that the flux lines at any time along the circumferential direction are similar with the sine waves with two cycles. As the saturation effect is changing all the time, the effective value of flux lines at $t=1.0 \mathrm{~s}$ is larger than the effective value of that at $\mathrm{t}=0.1 \mathrm{~s}$. During the starting transient operation, the flux lines passing through the stator slot bridge are approximately circumferential. Hence, the flux lines cross the circumferential line which located between the inner stator surface and the upper slot surface is smaller. It should be pointed out that the circumferential distribution of the flux lines which pass through the rotor slot bridge, as shown in Fig. 9(c), is similar with the circumferential distribution of the flux lines passing through the stator slot bridge.

In Fig. 9 (b) and Fig. 9 (d), the flux lines passing through the stator slot are almost circumferential. However, the flux lines passing through the stator teeth are almost radial. The flat parts of the curves denote the flux lines passing through the slot and the steep parts of the curves denote the flux lines passing through the slot. Moreover, the distribution of the flux lines passing through the rotor slot is much smoother than the distribution of the flux lines passing through the stator slot during starting transient operation. This can be explained because the stator slot is narrow and long while the rotor slot is round. Hence the flux lines passing through the stator slot are much larger than those of the rotor slot during starting transient operation.

For convenience of quantitative calculations of slot leakage inductance and slot leakage reactance, the magnetic flux linkages passing through the slot as well as the slot bridge were measured by the search coils, as shown in Fig. 10 (a). The stator current can be obtained by the software, as shown in Fig. 10 (b). Then the current of the rotor bar is obtained by the surface integral, as shown in Fig. 11. The leakage inductance can be obtained by

$$
L=\frac{\Delta \psi}{\Delta i}
$$

where $\Delta \psi$ denotes the increment of the flux linkage, and $\Delta i$ denotes the increment of the current.

The inductance is time-varying because of the nonlinear property of the material. The average stator slot leakage inductance and the average rotor slot leakage inductance 


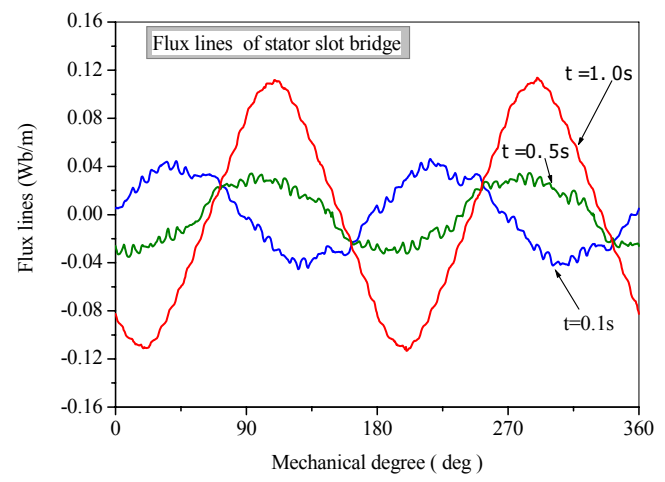

(a)

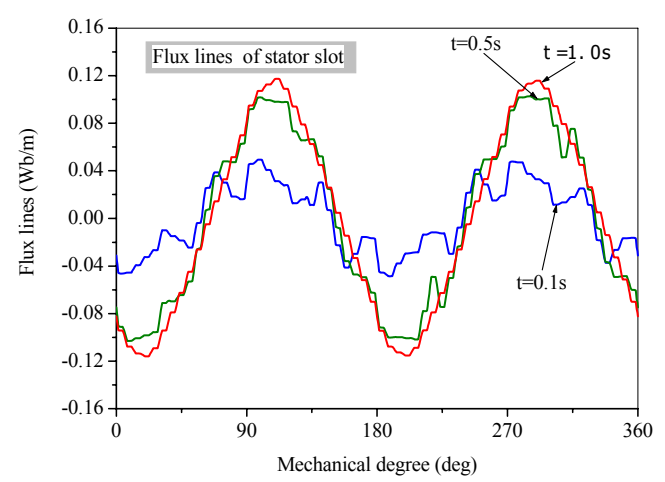

(b)

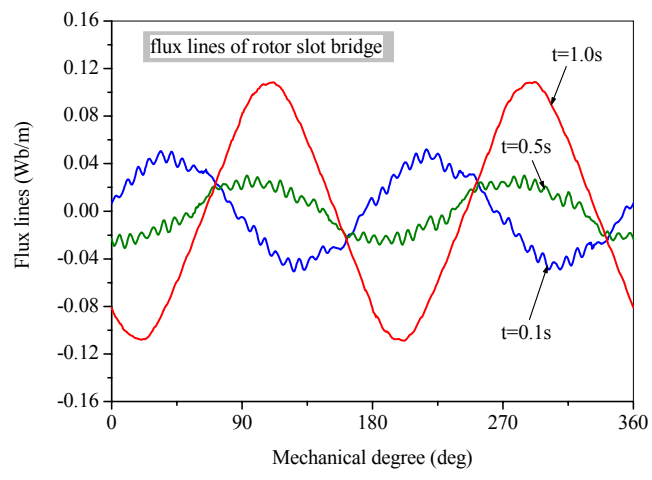

(c)

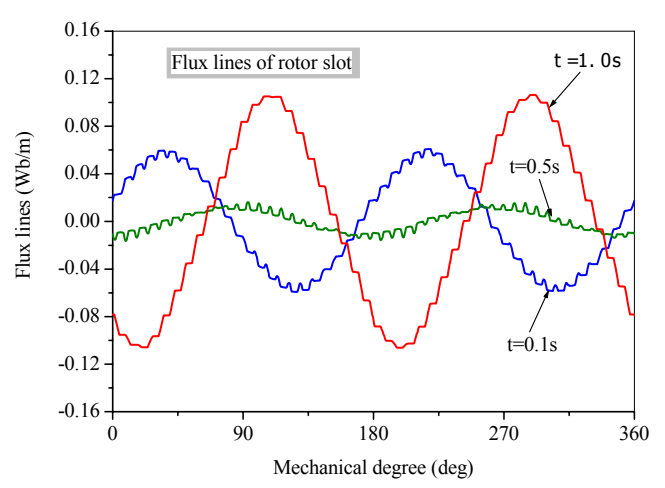

(d)

Fig. 9. (a) The circumferential flux lines pass through the stator slot bridge; (b) The circumferential flux lines pass through the stator slot; (c) The circumferential flux lines pass through the rotor slot bridge; (d) The circumferential flux lines pass through the rotor slot.

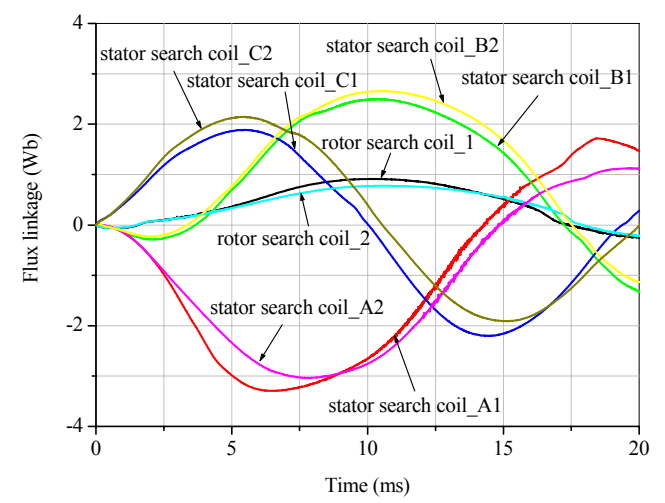

(a)

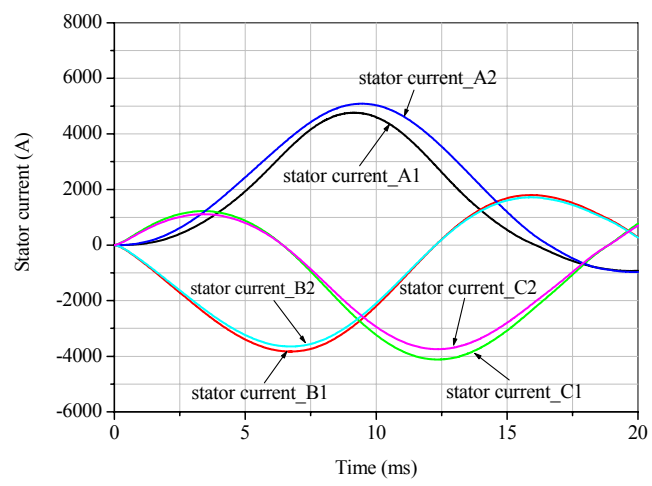

(b)

Fig. 10. (a) Distribution flux linkage; (b) Distribution of stator current.

are obtained by calculating the mean value of a cycle. For the slot type 1, the magnitudes of the stator slot leakage inductances of phase A, B and C are 1.4, 1.2 and 1.8 millihenry during starting transient operation. Similarly, for the slot type 2, the magnitudes of the stator slot leakage inductances of phase A, B and C are 1.2, 1.0 and 1.8 millihenry. The rotor slot inductances are shown in Fig.11. It can be seen from Fig.11 that stator slot types have little influence on the rotor leakage inductance except at some special moment. The sharp peaks can be explained because the current may reach zero at some time. We calculate the average slot leakage inductance by getting rid of the sharp peaks and the average slot leakage inductances are 20.8 microhenry and 19.5 microhenry, respectively.

The analytical results and the finite element analysis results, as shown in Table 2, show that the results obtained by finite element method results are very close to the results obtained by analytical method, so the method proposed is verified. The stator slot leakage reactance is much larger than the rotor leakage reactance during the 


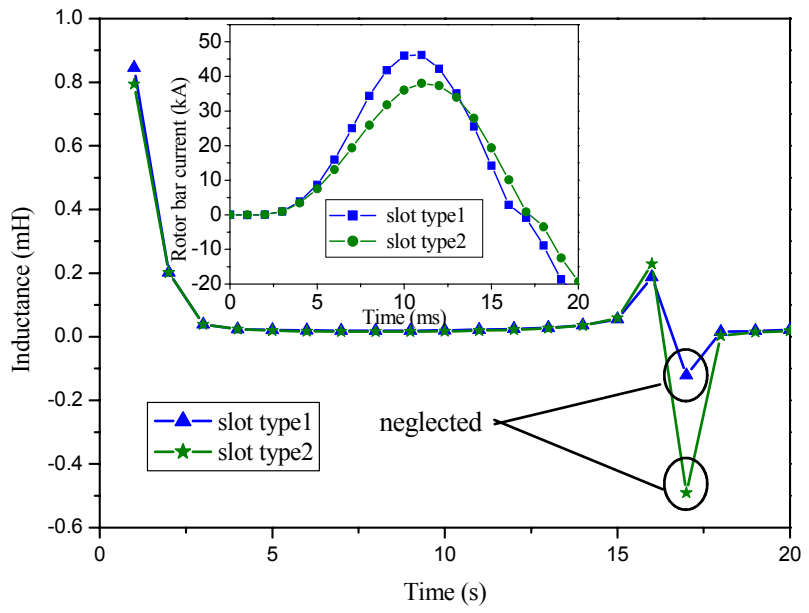

Fig. 11. The rotor current and inductance

Table 2. Leakage reactance during starting process

\begin{tabular}{c|c|c|c|c}
\hline \multirow{2}{*}{ Item } & \multicolumn{2}{|c|}{ Slot type 1 } & \multicolumn{2}{c}{ Slot type 2 } \\
\cline { 2 - 5 } & $\begin{array}{c}\text { Analytical } \\
\text { method }\end{array}$ & $\begin{array}{c}\text { Finite } \\
\text { element } \\
\text { method }\end{array}$ & $\begin{array}{c}\text { Analytica } \\
\text { 1 method }\end{array}$ & $\begin{array}{c}\text { Finite } \\
\text { element } \\
\text { method }\end{array}$ \\
\hline $\begin{array}{c}\text { Rotor leakage } \\
\text { reactance of a } \\
\text { single slot }(\mathrm{m} \Omega)\end{array}$ & 0.31 & 0.32 & 0.31 & 0.31 \\
\hline $\begin{array}{c}\text { Stator leakage } \\
\text { reactance of } \\
\text { Phase } \mathrm{A}(\Omega)\end{array}$ & 8.81 & 8.79 & 7.99 & 7.54 \\
\hline
\end{tabular}

starting transient operation. Moreover, the leakage reactance the stator with the second type slot is smaller than the leakage reactance of the stator with the first type slot.

\section{Conclusion}

This paper studies the slot leakage reactance of submersible motor during starting transient operation. For the two typical stator slot types, the inclination $\alpha$ has a great influence on the slot permeance factor, however, the radius $R_{0}$ has little impact on the slot permeance factor. The flux linkages which pass through the rotor slot bridge are the primary components and the skin effect factor of the rotor bar is small because of the circular shape slot.

The finite element results show that the starting torque and the starting currents of the slot type 2 are larger than those of the slot type1. The leakage flux which passes through the stator slot is larger than the leakage flux which passes through the stator slot bridge. However, the leakage flux which passes through the rotor slot is smaller than that of the rotor slot bridge. Furthermore, the flux lines passing through the slot as well as the slot bridge are approximately circumferential.

In addition, the stator slot leakage reactance is much larger than the rotor leakage reactance during the starting transient operation. Finally, the results obtained by finite element method are very close to the results obtained by analytical method.

\section{Acknowledgements}

This work was supported by the National Natural Science Funds of China (No. 51177033 and No. 51377039), and Anhui Province Key Laboratory of Large-Scale Submersible Electric Pump and Accoutrements.

\section{References}

[1] P.D. Agarwal, and P.L. Alger. "Saturation factors for leakage reactance of induction motors," Transactions of the Power Apparatus and Systems. Vol. 79, No.3, pp.1037-1042, Oct. 1960.

[2] S.A.Swann, and J.W. Salmon. "Effective resistance and reactance of a solid cylindrical conductor placed in a semi-closed slot," Proceedings of the IEE-part C:Monographs. Vol. 109, No.16, pp. 611-615, July. 1962.

[3] T.S. Birch, and O.I. Butler, "Permeance of closedslot bridges and its effect on induction-motor-current computation", Proceeding of the Institution of Electrical Engineers, Vol. 118, No. 1, pp. 169-172, Jan. 1971.

[4] Juha Pyrhonen, Tapani Jokinen, and Valeria Hrabovcova. Design of rotating electrical mechines. John Wiley\& Sons, Ltd, 2008, pp. 234-244.

[5] H. Grop, J. Soulard, and H. Persson, "Stator slot leakage in AC-machines equipped with fractional conductor windings," International Conference on Electrical Machines and Systems, pp.1-6, 2009.

[6] Pavel Ponomarev, Pia Lindh, and Juha Pyrhonen. "Effect of slot-and pole combination on the leakage inductance and the performance of tooth-coil permanent magnet synchronous machines", IEEE Trans. Ind.Electron., Vol.60, No.10, Oct.2013.

[7] S. Salon, D. Burow, M. DeBortoli, and C. Slavik. "Effects of slot closure and magnetic saturation on induction machine behavior", IEEE Trans. Magn., Vol.30, No.5, pp.3697-3700. Sept.1994.

[8] Yanping Liang, Xu Bian, Honghao Yu, Lei Wu, and Lichao Li. "Analytic algorithm for strand slot leakage reactance of the transposition bar in an AC machine", IEEE Transactions on Ind. Electron., Vol. 61, No. 10, pp. 5232-5240. Oct.2014.

[9] S. Williamson, A.C.G.I., M.I.E.E., and M.C. Begg. "Calculation of the bar resistance and leakage reactance of cage rotors with closed slots" IEE Proceedings, Vol. 132, no. 3, pp. 125-132, May. 1985. 


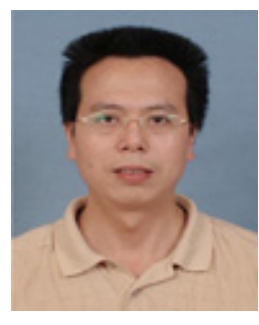

Xiaohua Bao $\mathrm{He}$ received the B.S. degree in 1996, the M.Sc. degree in 2002 and the Ph.D. degree in 2008, all in electrical engineering from Hefei University of Technology, Hefei, China. He joined the School of Electrical Engineering and Automation, Hefei University of Technology and was promoted to Professor, in 2012. He was a visiting Scholar with Virginia Polytechnic Institute and State University, U.S. His main research interests are in the field of motor design, magnetic field analysis, and finite element analysis.

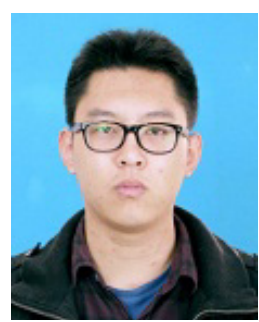

Chong Di He received the B.S. degree in 2014 in electrical engineering from Hefei University of Technology, Hefei, China. He joined the School of Electrical Engineering and Automation, Hefei University of Technology as a postgraduate. His main research interests are in the field of motor design, finite element analysis and electromagnetic field analysis.

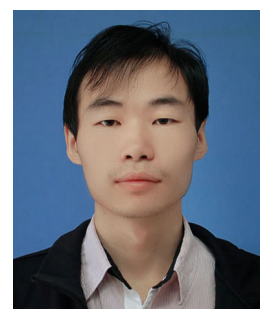

Yong Fang He received the B.S. degree in 2012 in electrical engineering from Hefei University of Technology, Hefei, China. He joined the School of Electrical Engineering and Automation, Hefei University of Technology as a postgraduate. His main research interests are in the field of motor design, finite element analysis and electromagnetic field analysis. 